\title{
The Difference between White and Red Ginseng: Variations in Ginsenosides and Immunomodulation*
}

\author{
Authors \\ Affiliations \\ 1 LU-European Center for Chinese Medicine, Leiden \\ University, Leiden, The Netherlands \\ 2 Institute of Biology Leiden (IBL), Leiden University, Leiden, \\ The Netherlands \\ 3 Jilin Ginseng Academy, Changchun University of Chinese \\ Medicine, Changchun, Jilin Province, P. R. China \\ 4 Jilin ZiXin Pharmaceutical Co., Ltd., Changchun, Jilin \\ Province, P. R. China \\ 5 SU Biomedicine, Leiden, The Netherlands
}

Min $\mathrm{He}^{1,2}$, Xin Huang ${ }^{3}$, Shuying Liu ${ }^{3}$, Chunsheng Guo ${ }^{4}$, Yufei $\mathrm{Xie}^{2}$, Annemarie H. Meijer ${ }^{2}$, Mei Wang ${ }^{1,2,5}$

\section{Key words}

Panax ginseng, Araliaceae, white ginseng, red ginseng, immunomodulation, zebrafish model

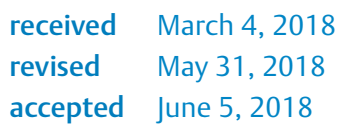

Bibliography

DOI https://doi.org/10.1055/a-0641-6240

Published online June 20, 2018 | Planta Med 2018; 84: 845854 ㄷ Georg Thieme Verlag KG Stuttgart · New York । ISSN 0032-0943

\section{Correspondence}

Dr. Mei Wang

LU-European Center for Chinese Medicine, Leiden University Sylviusweg 72,, Leiden 2333BE, Netherlands

Phone: + 31715272727

m.wang@biology.leidenuniv.nl

\section{ABSTRACT}

Ginseng Radix (Panax ginseng) is one of the most commonly used herbs worldwide for the treatment of inflammation-related diseases among others, supported by ancient historical records. Throughout this long history, the large-scale cultivation of ginseng created an increasing demand for long-term storage of the harvested plant material, accelerating the development of post-harvesting procedures. Dried white ginseng and processed (steamed) red ginseng are the products of the two most common traditional post-harvest processes. Although there are a significant number of reports on practice-based therapeutic applications of ginseng, science-based evidence is needed to support these uses. Using a reverse pharmacology approach in conjunction with high-throughput techniques and animal models may offer clear, simple paths for the elucidation of the mechanisms of activity of herbal medicines. Moreover, it could provide a new and more efficient method for the discovery of potential drug candidates. From this perspective, the different chemical compositions of white ginseng and red ginseng could very likely result in different interactions with signaling pathways of diverse biological responses. This paper provides an overview of white ginseng and red ginseng, mainly focusing on their chemical profile and immunomodulation activities. Synergistic effects of ginseng herbal drugs with combinations of other traditional herbal drugs or with synthetic drugs were reviewed. The use of the zebrafish model for bioactivity testing greatly improves the prospects for future ginseng research.

\section{Introduction}

Ginseng Radix (Panax ginseng C. A. Meyer, Araliaceae) is one of the most widely used medicinal herbs in the world, particularly in the Far East, China, Japan, and Korea. The most frequently used part of this plant for traditional therapeutic applications is the root (rhizome and/or radix). Ginseng has a long history of traditional applications, with records of its medicinal use as an adaptogen, for the restoration, repair, or healing of the human body, or prevention of disease. Both market demand and academic research have increased significantly in recent years, while its efficacy has been disputed in many cases. One of the potentially most important reasons for these controversies might lie in the absence of a correct differentiation of two types of processed ginseng material. Besides that, other critical factors such as the geographical origin, development stage or age, storage, type of extract, among others, may also contribute to variations in the results. In this manuscript we focus on the two traditional ginseng preparations that are mainly used nowadays, i.e., white ginseng (WG) and red ginseng (RG). After searching the databases Pubmed/MEDLINE, Embase, and Biosis (for English papers) as well as CNKI (for Chinese papers), with the key words "ginseng" or "white/unpro-

* Dedicated to Professor Dr. Robert Verpoorte in recognition of his outstanding contribution to natural product research. 


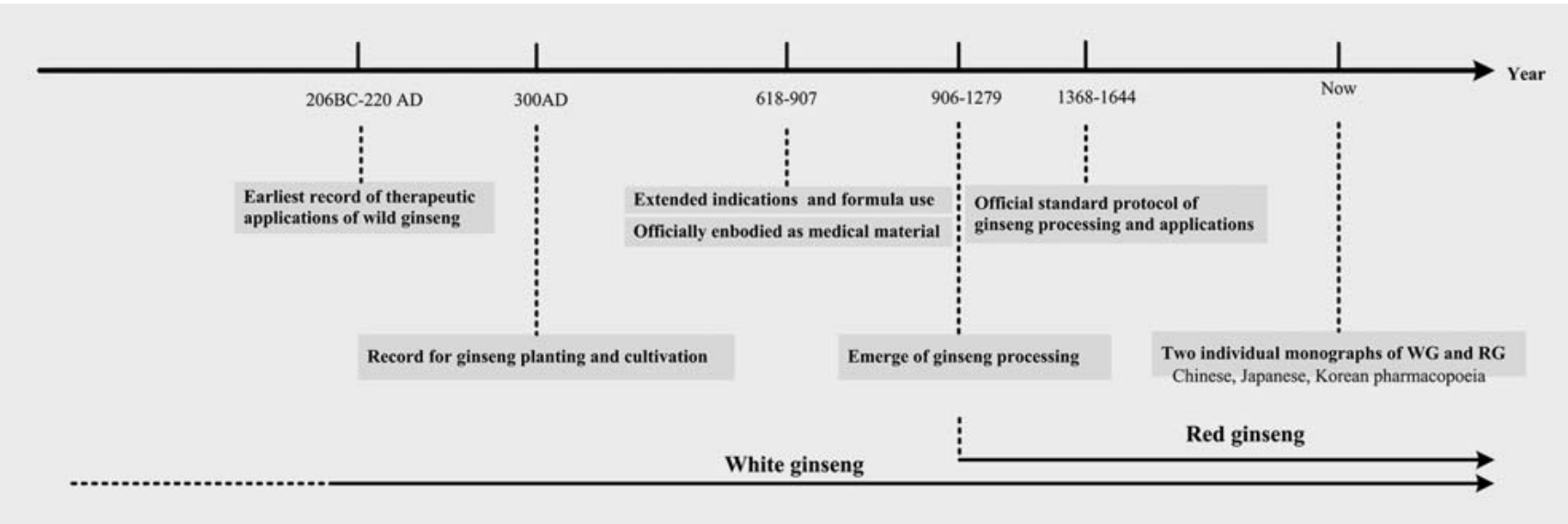

- Fig. 1 Historical development and uses of white/red ginseng in China. Stage 1: The earliest records of therapeutic applications of wild ginseng can be found in a Chinese ancient book, Shen-Nong's Classic of Materia Medica (also known as "Shen-Nung Pen-Ts'ao Ching" or "Shin-Nong-BonCho-Kyung", in Chinese: "Shen-Nong bencao jing"). The texts were compiled during the Han Dynasty (206 BC-220 AD) and were considered to be a documentation of Shen-Nong who lived around 2800 BC [2]. Stage 2: With a period of enlarged demands, the emergence of ginseng planting/ cultivation began at the end of the jin Dynasty ( $300 \mathrm{AD}$ ), as mentioned in an ancient Chinese history book "Book of Jin-Shi Le Part" (texts compiled and re-edited during the Tang dynasty around $648 \mathrm{AD}$ ). Stage 3: During the Tang Dynasty (618-907), ginseng was characterized by a flourishing of indications for different therapeutic purposes and with multi-formulations in Beiji Qianjin yaofang (Invaluable prescriptions, finished in 652 AD); this was later transmitted to Japan, Korea, and other Asian countries. In addition, ginseng was recorded as a plant in the "Materia Medica", the first Chinese pharmacopoeia (newly revised canon of Materia Medica; in Chinese: Xinxiu Bencao) published in 659 AD by the Chinese officials. Stage 4: The earliest record of processed ginseng corresponds to the Song Dynasty (960-1279 AD) [3]. Stage 5: The cultivation, processing, and applications of ginseng were detailed in Compendium of Materia Medica (in Chinese: Bencao gangmu), which was written by Shizhen Li in the Ming Dynasty (1368 1644 AD) and is considered to be the most important source of Chinese herbal medicine for the modern Chinese pharmacopoeia. Stage 6: This is the current developing stage of official individual monographs of WG and RG in the CP 2015. The differences between WG and RG in functional characters and therapeutic applications as well as their similar applications such as their benefits for blood nourishing and weakness (lack of energy) are recorded in detail [4].

cessed ginseng" or "red/processed/steamed ginseng” or "ginsenosides", along with "immune" or "immunomodulation", there were approximately 3400 papers (349 in English and 3209 in Chinese) that have been published since the 1980s. Within these papers, 267 were about $P$. ginseng C. A. Meyer extracts (35 in English and 242 in Chinese) and ginsenosides from ginseng (105 in English and 278 in Chinese) under the topic of immunomodulation against cancer or inflammation. Based on the information from the literature, both types of ginseng, WG and RG, possess different chemical components that could result in different therapeutic activities, especially in cases such as the modulation of the immune system. This paper presents a review of the comparative studies of WG and RG, focusing mainly on their composition and efficacy.

\section{Historical Development of White and Red Ginseng}

P. ginseng C. A. Meyer has many synonyms, such as Ren shen, Mountain Ginseng, Korean Ginseng, or Asian ginseng. The name "ginseng" is also used for many other plants, such as American ginseng (Panax quinquefolius L., in Chinese: Xiyangshen), Noto (pseudo) ginseng [Panax notoginseng (Burk) F. H. Chen, in Chinese: Sanchi/Sanqi], and Japanese ginseng [Panax japonicus, (T. Nees.) C. A. Meyer], but $P$. ginseng C. A. Meyer is the still most commonly used species [1]. The historical development of ginseng as a me- dicinal plant can be summarized in six major stages ( $\bullet$ Fig. 1): Stage 1, 206 BC-220 AD: The earliest records of therapeutic applications of wild ginseng date back to this period; Stage 2, $300 \mathrm{AD}$ was characterized by an increase in the demand and consequent emergence of planting and cultivation; Stage 3, 618-907, during this time the indications for its use were extended, and multi-formulas were created having been included in the official Materia Medica; Stage 4, 960-1279 AD witnessed the emergency of ginseng processing, accelerated by the increased demand of indications and the need for long-term storage of harvested material; Stage 5, $1368 \sim 1644$ AD marked the appearance of the official standard protocol of ginseng processing and applications; and Stage 6, now is the current developing stage in which separate monographs of WG and RG have been included in the Chinese Pharmacopoeia (CP 2015) [2], the Korean Pharmacopoeia [3], and the Japanese Pharmacopoeia [4].

As summarized above, throughout thousands of years, ginseng evolved from a wild herb to being the product of large scale plantations, requiring the development of post-harvesting and long-term storage methods to prevent its degradation due to insects, moulds, and fungi. Most of the herbs used in traditional Chinese medicine must be submitted to some type of post-harvesting processing. This processing is not only directed at ensuring a better stability during storage, but may have other purposes according to the herb, such as achieving consistent quality and better efficacy, reducing toxic or undesired side effects, modifying the chemical composition to increase solubility, the removal of 
the unpleasant smell of certain drugs, or even the preparation of drug material with completely different therapeutic properties to the original raw material [5]. The simplest post-harvesting procedure is the dehydration of the material by drying in the sun (naturally under sunshine). In the case of ginseng, the result of this treatment is WG (dried ginseng/unprocessed ginseng, Chinese: Bai shen). This traditional procedure may not always guarantee the long-term storage of plant material due to climatic variations and transportation times. Thus, over time, a number of alternative processing procedures appeared, such as steaming with or without additional excipients (e.g., alcohol or honey), boiling, and stir-frying. Among these, the most common process is steaming the ginseng as following: after harvest ginseng, the side roots of ginseng will be removed and washed in clean water, then the cleaned ginseng will be steamed $\left(100^{\circ} \mathrm{C}\right)$ for $2-3 \mathrm{~h}$ until the roots color becomes yellow. Then heat-dry or sun-dry the steamed ginseng [5]. This procedure can be repeated for several cycles. When the steaming is done at a high temperature for sterilization, followed by drying, a Maillard reaction [6] occurs and the ginseng acquires a reddish or brown tinge that gives the material the name red ginseng (RG, processed ginseng/steamed ginseng; in Chinese: Hong shen/Hongsam). The longer the steaming, the darker the resulting color of the ginseng. Black ginseng is in fact the product of a 9-cycle steaming process. However, WG and RG are the two traditional preparations that are most commonly used.

Red ginseng was originally developed with the only purpose of improving the preservation of ginseng for long-term storage. However, as has been observed in general for most plant material, the difference in post-harvest treatments can result in changes in the chemical composition and biological activities of the material [7]. This proved to be the case for ginseng also. Chinese herbal medicines are traditionally classified according to the sensations they evoke in the patient and the patient's response, resulting in descriptive characterizations such as taste, warm/cold, and toxic/ nontoxic. Such classifications have now been scientifically validated $[8,9]$. Based on this theory, both WG and RG are considered to have "warm" functional characters, but this property may be enhanced by the processing of RG $[10,11]$. While WG is traditionally considered relatively mild and has the specific function of quenching thirst (one of the main symptoms of diabetes in ancient descriptions), it is also beneficial for the treatment of insomnia and pulmonary disease. RG is more suitable for weakness in aging patients, for syndromes of excessive bleeding during puerperium, or postsurgical weakness. These very different functional characters of WG and RG and their resulting therapeutic applications are also recognized in the CP 2015 to the extent that there are now two separate monographs for WG and RG, reflecting their differences in therapeutic indications. However, according to the CP 2015 [2], WG and RG share some similar applications such as their benefits for blood nourishing and fatigue (lack of energy) [2]. There is, however, a need for much more scientific evidence to support the different therapeutic applications that are proposed, as well as an explanation of the mechanisms of their purported pharmacological activities. Nonetheless, when searching for justifications for the inconsistency in results of pharmacological or clinical studies with ginseng, it is important to consider that many scientific researchers may have been unaware of the existence of these two processed forms of ginseng, and published results actually correspond to different materials. This could account for the variation of the scientific results reported so far. We thus considered that it was very important to provide information that could contribute to distinguish these two forms of ginseng, creating awareness of the importance of their differences.

\section{Differences in Chemical Composition of White Ginseng and Red Ginseng}

Ginseng saponins, or ginsenosides, are the major active principles of ginseng. They are triterpenoidal glycosides with a high chemical variation, depending on the linkage position and number of sugars on the aglycone skeleton. In general, based on the structure of aglycone, ginsenosides can be classified into three different types: 1) dammarane type, that includes protopanaxadiols (PPDs) with sugar substituted on C-3, C-20, or both positions, such as $R b_{1}, R b_{2}, R b_{3}, R c, R d, R g_{3}, R h_{2}$, and compound $K$; and protopanaxatriols (PPTs) with sugar substitutes on C-6, C-20, or both positions, such as $\mathrm{Re}, \mathrm{Rf}, \mathrm{Rg}_{1}, \mathrm{Rg}_{2}$, and $\mathrm{Rh}_{1}$ ); 2) oleanane (oleanolic acid) type, such as Ro and polyacetyleneginsenoside Ro; and $c$ ) ocotillol type, such as majonosides $R_{1}$, majonosides $R_{2}$, vina- $R_{1}$, vina- $R_{2}$, vina- $R_{6}$, vina- $R_{14}, 24$-pseudoginsenoside $R T_{4}$, and pseudoginsenoside $F_{11}$ [12-15]. These ginsenosides can be interconverted ( $\vee$ Fig. 2). In P. ginseng C. A. Meyer, only dammarane-type (both PPD and PPT type) and oleanane-type ginsenosides are detectable, while the ocotillol type exist mainly in the $P$. quinquefolius L. To date, more than 50 different ginsenosides have been identified in ginseng [16-19]. The content of ginsenosides in ginseng varies according to the growth/harvest location, harvest season, age, and part of the plant [18-28].

Many chemical reactions can occur during the processing (especially when submitted to heat), and these structural conversions of ginsenosides lead to the main differences between RG and WG. The structural conversions depend both on the temperature used and the duration of the process. The relative differences in the ginsenoside content of WG and RG are displayed in

- Table 1. In general, PPD-type ginsenosides (Rb2, Rb3, Rc, Rd, Re1, F2, Ro) as well as PPT-type ginsenosides (Re, Rf, Rg1, NotoR1) are relatively more abundant in WG [26]. Conversely, ginsenosides (20S- and 20R-) Rg3, Rh1, and Rh2 are considered to be characteristic components of RG $[29,30]$. Higher levels of PPDtype ginsenosides (Ra1, Ra2 and Ra3, Rb1) and PPT-type ginsenosides (Rg4) are also found in RG [26]. In WG, malonyl ginsenosides $\mathrm{mRa} 1 / \mathrm{Ra} 2, \mathrm{mRa} 3, \mathrm{mRb} 1, \mathrm{mRb} 2, \mathrm{mRb} 3, \mathrm{mRc}, \mathrm{mRd}$, mRe, and $\mathrm{mRg} 1$ are considered to be characteristic components that are decreased by processing [26, 31,32]. The ginsenoside 20S-Rg2 is relatively higher in WG, while $20 R-R g 2$ is higher in RG [26]. Many acetylated ginsenosides (quinquenoside R1 and ginsenosides Rs 1 and Rs2) are relatively abundant in RG because of the inactivation of the deacetylating enzyme with steaming [30,33]. In addition, contents of the less polar ginsenosides (F4, F5, Rk1, Rg2, Rg5, Rg6, 20R-Rs3, 20S-Rs3, and Rs4) are observed in RG because of their bioconversions during processing at high temperatures [34-37]. It was also reported that the bioaccessibility of WG and 

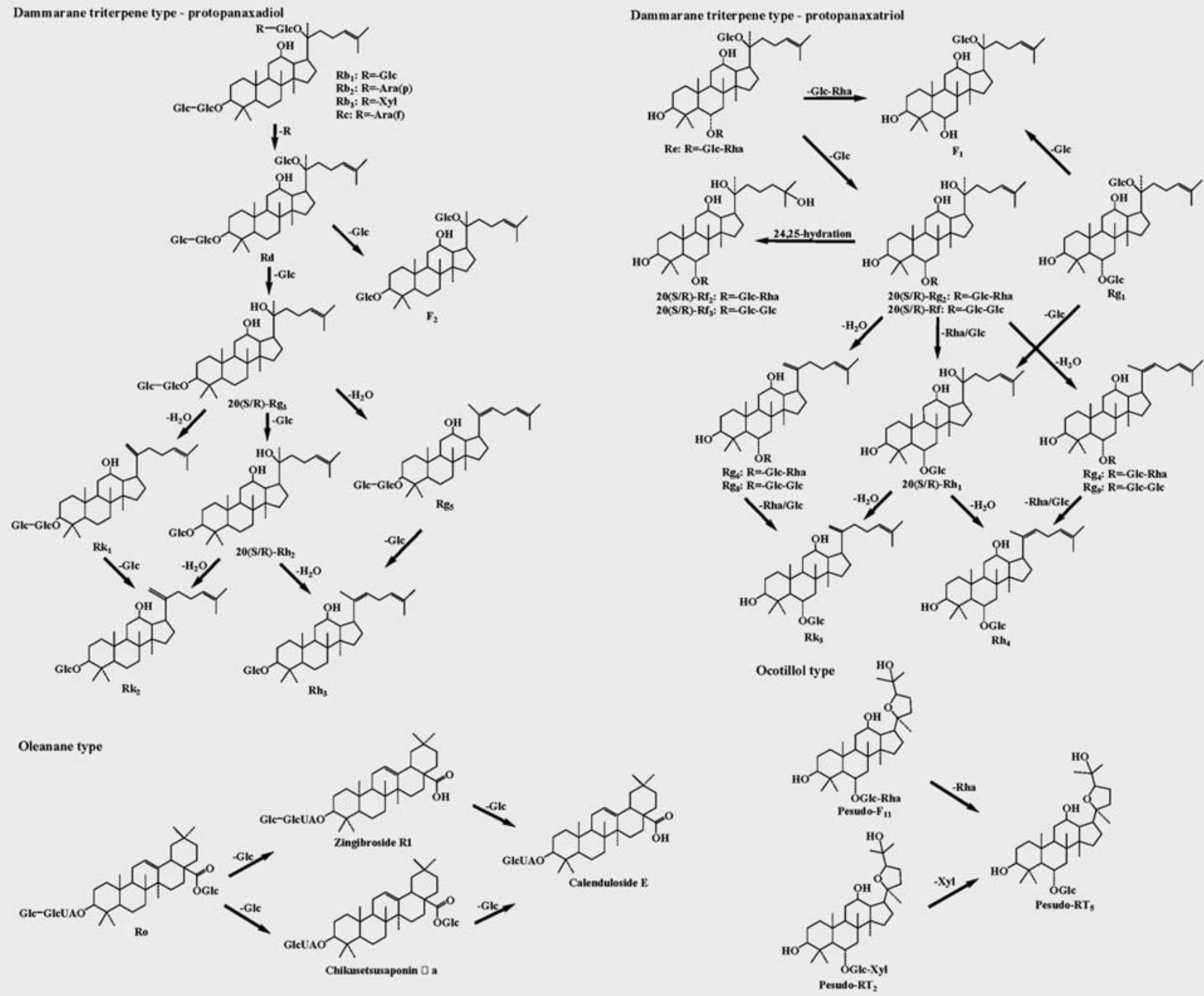

- Fig. 2 Chemical structures of ginsenosides and their interconversions. Conversion pathways are summarized based on references [16,29-32].

RG may be different [38]. Therefore, not only the differences in qualitative composition, but also differences in quantitative bioavailability and qualitative bioconversion should be considered when further studying the pharmacological differences between WG and RG.

Apart from ginsenosides, polysaccharides are another class of important active components in ginseng. The concentration of reducing sugars (acidic polysaccharides) detected in RG are higher than in WG due to the degradation of sugar components during processing $[39,40]$. Maltol and its glucosides have been considered artificially synthesized products because of the Maillard reaction in the processing of RG [41]. On the other hand, the total level of phenolic acids and insoluble-bound phenolic acids are relatively higher in WG, while trans-ferulic acid and esterified phenolic acids are higher in RG [42]. The volatile flavor compounds 2-furanmethanol and 3-hydroxy-2-methyl-4H-pyran-4-one are considered to be the major characteristic components of WG, while
RG contains 1,2-benzenedicarboxylic acid dibutyl-ester and 2-furanmethanol instead [43]. Alkaloids have also been detected in both types of ginseng.

\section{Pharmacology: Immunomodulation}

Among the many bioactivities of ginseng reported in the literature, in this review we have focused on immunomodulation. There are a number of reasons for our choice. In the first place, the traditional indications of ginseng as an adaptogenic comprise activities directed mainly at nourishing, strengthening, or restoration of the homeostasis of the body after a long illness or due to aging. From a modern perspective, these activities are related to regulations of the immune system [44]. Secondly, based on scientific research, ginseng has multiple biological bioactivities, such as vasorelaxation (angio-modulation), but it also has antioxidant, anti-inflammatory, anticancer, and antidiabetic-related (for obe- 
- Table 1 Relative content of ginsenosides in WG and RG based on literature studies (references [26, 33-41]).

\begin{tabular}{|c|c|c|c|c|c|c|c|c|c|c|c|}
\hline PPD-type & WG & RG & PPT-type & WG & RG & $\begin{array}{l}\text { Malonyl } \\
\text { ginsenosides }\end{array}$ & WG & RG & $\begin{array}{l}\text { Other transformed } \\
\text { ginsenosides }\end{array}$ & WG & RG \\
\hline Ra1 & + & ++ & $\mathrm{Rg} 4$ & + & ++ & $\mathrm{mRb} 1$ & ++ & + & Quinquenoside R1 & $\mathrm{N} / \mathrm{A}$ & + \\
\hline $\mathrm{Ra} 2$ & + & ++ & $\mathrm{Rg} 4$ & + & ++ & $\mathrm{mRb} 2$ & ++ & + & Rs1 & $\mathrm{N} / \mathrm{A}$ & + \\
\hline Ra3 & + & ++ & Rh1 & + & ++ & $\mathrm{mRc}$ & ++ & + & Rs2 & $\mathrm{N} / \mathrm{A}$ & + \\
\hline Rb1 & + & ++ & $\operatorname{Re}$ & ++ & + & $\mathrm{mRd}$ & ++ & + & Rk1 & - & ++ \\
\hline $\mathrm{Rg} 3$ & + & ++ & $\mathrm{Rf}$ & ++ & + & $\mathrm{mRe}$ & ++ & + & 20R-Rg2 & - & ++ \\
\hline Rh2 & + & ++ & $\mathrm{Rg} 1$ & ++ & + & $\mathrm{mRg} 1$ & ++ & + & $\mathrm{Rg} 5$ & - & ++ \\
\hline Rb2 & ++ & + & Noto-R1 & ++ & + & $\mathrm{mRa} 1 / \mathrm{mRa} 2$ & ++ & + & $\operatorname{Rg} 6$ & - & ++ \\
\hline Rb3 & ++ & + & $20 S-R g 2$ & ++ & + & mRa3 & ++ & + & Rs3 & - & ++ \\
\hline Rc & ++ & + & & & & & & & Rs4 & - & ++ \\
\hline $\mathrm{Rd}$ & ++ & + & & & & & & & F4 & + & ++ \\
\hline Re1 & ++ & + & & & & & & & F5 & + & ++ \\
\hline F2 & ++ & + & & & & & & & & & \\
\hline Ro & ++ & + & & & & & & & & & \\
\hline
\end{tabular}

sity) properties. All these biological effects are closely connected to inflammation and the immune system. Lastly, the structures of the terpenoid saponins currently reported have some similarities to steroids, which play a role in the anti-inflammatory effects or the modulation of the immune system [45-49]. The partial overlapping of the chemical composition of WG and RG suggests that while they may have some similar biological activities, they also have many differences. These differences in immunomodulatory activities should be more exhaustively evaluated since they could be exploited for better personalized applications and treatments, and also eventually lead to the discovery of new active molecules or treatment strategies.

The vast majority of published reports do not specify whether the investigations were done with WG or RG. We thus selected literature data related to immunomodulation ( $\bullet$ Table 2 ). In this summary, it is clear that some studies reported effects consistent with potential immunoactivation, while others pointed towards immunosuppression. Could these differences be explained by the use of different ginseng materials (RG/WG) and/or a variation of the content/ratio of ginsenosides? It has been reported, for example, that variations in the ratio of $\mathrm{Rg} 1 / \mathrm{Rb} 1$ can lead to an opposing effect on angiogenesis [50]. As mentioned, the post-harvest processing can alter the ratio of various ginsenosides. Other possible explanations could be totally unrelated to the processing method, lying rather in differences in the biological responses when using different cell-based assay systems. Therefore, in vivo assays should be favored since they are more reliable for the validation of pharmacological effects.

The significant differences in the relative content of certain ginsenosides ( $\bullet$ Table 2 ) in RG and WG could provide an opportunity to analyze the biological effects of different ginsenosides contained in them. In $>$ Fig. $\mathbf{3}$, we summarized the cross-talking of the immunomodulatory effects of ginsenosides classified by their relative concentration in WG and RG. This data is based on litera- ture information, including enzymes, genes, proteins, and inflammatory-based factors. This summary focuses mainly on antioxidant capacity, anti-inflammatory, anticancer activity, and angiogenesis, as well as their detailed potential pathways ( $\bullet$ Fig. $\mathbf{3}$ ) [14]. As there are significant differences in the ratio and content of various ginsenosides ( $\bullet$ Table 1 ), the integrated systems view may reveal some differences in targets and effects of WG and RG (॰ Fig. 3).

In particular, in the field of inflammation, most studies have focused mainly on the anti-inflammatory activities of the individual ginsenosides Rb1, Rh1, Rg1, Rg5, and Re [51]. The mechanisms of action that have been revealed include the inhibition of enzyme expression (such as cyclooxygenase) and the production of proinflammatory chemokines, cytokines, prostaglandins, and interleukins [44]. Among these ginsenosides, Rg1 and Re are more abundant in WG, while the rest are all relatively more abundant in RG. This may explain the fact that both WG and RG have potential anti-inflammatory activities that relate to immunomodulation. The significantly greater anti-inflammatory effects exhibited by RG might be due to their higher inhibitory effect on the synthesis of NO and IL-6, but also of more inflammatory-related pathways/mediators such as NF-KB, TLR, MyD88, IgE level, and their radical scavenging capacity [34,52-57]. The relationship between angio-modulation, inflammation, and the immune system has been well established. Pharmacological studies of ginseng on angio-modulation refer mainly to ginsenosides Rb1, Rg1, Rg3, Re, $\mathrm{Rd}$, and Rh1. The mechanisms that have been described involve the activation of nitric oxide (NO) production to reduce reactive oxygen species (ROS) production, as well as the activation of $\mathrm{PI} 3 \mathrm{~K}, \mathrm{AKT} / \mathrm{PKB}$, and the $\beta$-catenin/T cell factor-dependent pathway via the glucocorticoid receptor (GR) $[49,58,59]$. In the field of cancer research, a great number of studies have shown the anticancer effects of ginseng or different ginsenosides, though to date no comparison between the anticancer effects of WG 
- Table 2 Multiple immunomodulation pathways of ginseng extract/pure ginsenosides (no distinction of WR/RG is made).

\begin{tabular}{|c|c|c|c|c|}
\hline $\begin{array}{l}\text { Ginseng } \\
\text { extract/ } \\
\text { ginsenoside }\end{array}$ & $\begin{array}{l}\text { Reported activation of factors related } \\
\text { with immunomodulation }\end{array}$ & Ref. & $\begin{array}{l}\text { Reported suppression of factors related } \\
\text { with immunomodulation }\end{array}$ & Ref. \\
\hline \multirow[t]{4}{*}{$\begin{array}{l}\text { Ginseng extract } \\
\text { (including gin- } \\
\text { senosides) }\end{array}$} & $\begin{array}{l}\text { Stimulate proliferation of macrophages; enhance } \\
\text { production of IL-12 (both in mRNA and protein lev- } \\
\text { els) via the Th1 response; enhance immunoglobulin } \\
\text { IgM, IgG, and IgA, and IL-2, IFN-y, IL-4, IL-10 levels; } \\
\text { activation of TLR-4 }\end{array}$ & [53-58] & & \\
\hline & increases endocytosis of dendritic cells & & $\begin{array}{l}\text { Inhibits maturation of dendritic cells; inhibits expression } \\
\text { of CD- } 40, C D 86, H L A-D R \text {, and CD1a; inhibition on pro- } \\
\text { duction of IL-12 in dendritic cells }\end{array}$ & [59] \\
\hline & Increase innatural killer cell activity & {$[57,60,61]$} & & \\
\hline & & & $\begin{array}{l}\text { Inhibits expression of CD-40, CD86, HLA-DR, and CD1a; } \\
\text { decrease of T-lymphocytes CD3+, CD4+8-, CD4-8+ }\end{array}$ & {$[57,59]$} \\
\hline \multirow[t]{3}{*}{ Polysaccharides } & $\begin{array}{l}\text { Enhances proliferation of T and B cells; activation of } \\
\text { macrophages to produce } \mathrm{NO}, \mathrm{H}_{2} \mathrm{O}_{2} \text {, IL- } 1 \mathrm{~b} \text {, RNF-a, } \\
\text { IL-6, TNF- } \alpha \text {, IL-12, IL- } 17 \text { and IFN- } \gamma \text {; activation of } \\
\mathrm{NF}-\mathrm{K} \text { B pathways (NF- } \kappa \mathrm{B}-\mathrm{p} 65 \text { expression); increases } \\
\text { phagocytic activity of macrophages }\end{array}$ & [62-69] & $\begin{array}{l}\text { Inhibits expression of TNF- } \alpha \text {, IL-1b, IL-6, IL-12, IFN- } \\
\text { gamma, IL-18, interferon-gamma, and TLR2, TLR4, } \\
\text { TLR9, MyD88, phosphor-JNK-1/2, phospho-p38 MAPK, } \\
\text { and NF-KB in macrophages }\end{array}$ & {$[68,69]$} \\
\hline & $\begin{array}{l}\text { Increases production of IL- } 12 \text { and TNF- } \alpha \text { in } \\
\text { dendritic cells }\end{array}$ & [67] & & \\
\hline & & & $\begin{array}{l}\text { Promotes generation of immunosuppressive regulatory } \\
\text { T cells (Tregs) }\end{array}$ & [70] \\
\hline $\mathrm{Rb} 1$ & $\begin{array}{l}\text { Enhances serum levels of IL-4 and IL-10 as well as } \\
\text { IFN- } \gamma, \text { IL-2, IL } 4, T N F-\alpha \text {, IgG } 1, \lg G 2 a \text {, and } \lg G 2 b\end{array}$ & [71] & Inhibition of TNF- $\alpha$ & [72] \\
\hline Rd & $\begin{array}{l}\text { Enhances expression of } \operatorname{lgG}, \lg \mathrm{g} 1 \text {, and } \mathrm{IgG} 2 \mathrm{~b}, \mathrm{IL}-2 \text {, } \\
\mathrm{IFN}-\gamma, \mathrm{IL} 4 \text {, and IL-10 }\end{array}$ & [73] & & \\
\hline $\mathrm{Rh} 2$ & & & Inhibition of NO production & [74] \\
\hline Compound K & Enhances nuclear protein binding to CRE & [75] & $\begin{array}{l}\text { Inhibits production/expression of iNOS, ROS, IL-1, IL-6, } \\
\text { MCP-1, mmp-3 and mmp-9 via MAPK, NF-kB pathways }\end{array}$ & [75] \\
\hline Rh1 & & & $\begin{array}{l}\text { Inhibits production of NO, ROS, TNF- } \alpha \text {; inhibits expression } \\
\text { of NF-KB, IRF-1, STAT1, JAK1, STAT1, STAT3, ERK }\end{array}$ & {$[74,76]$} \\
\hline \multirow[t]{3}{*}{ Rg1 } & $\begin{array}{l}\text { Increases production of IL- } 1 \text { by macrophages; } \\
\text { enhances mRNA expression of IL- } 2 \text { and IL-4; } \\
\text { stimulates VEGF and PI3K/Akt and } \beta \text {-catenin/ } \\
\text { T cell factor-dependent pathway via GR }\end{array}$ & {$[51,77]$} & & \\
\hline & Increases natural killer cell activity & [77] & & \\
\hline & $\begin{array}{l}\text { Enhances proliferation of lymphocytes; enhances } \\
\text { IL-2 and IL- } 4 \text { to induce Th2 in CD4+T cells }\end{array}$ & {$[78,79]$} & Decrease IFN-r in CD4+ T cells & [79] \\
\hline Rg5 & & & $\begin{array}{l}\text { Inhibition of IL- } 1 \mathrm{~b} \text { and TNF- } \alpha \text {, iNOS, and COX- } 2 \text { in } \\
\text { macrophages }\end{array}$ & [80] \\
\hline $\operatorname{Re}$ & $\begin{array}{l}\text { Activation of the insulin signaling pathway via } \\
\text { inhibition of JNK and NF- } K B \text { activation and inhibitor } \\
\text { of NF-KB degradation }\end{array}$ & [81] & & \\
\hline
\end{tabular}

and RG has been made [14,60-64]. The antitumor effect of individual ginsenosides refers mainly to ginsenosides that are abundant in RG (Rb1, Rg3, Rh1, Rh2, Rg5, and Rs4), and also to some ginsenosides that are abundant in WG (Rb2, Rc, Rd, Re, Rg1) [14, 26,60,61,65-69]. These results suggest that both WG and RG may have an anticancer effect, though their mechanisms or pathways may differ [70]. Additionally, polysaccharides showed an immunostimulatory effect to activate macrophages via the pathways of NF-KB and AP-1, as well as ERK, JNK, and TLR2 [71]. Water-soluble ginseng oligosaccharides help with lymphocyte proliferation [72]. The immunomodulatory and anti-inflammatory effects of ginseng polysaccharides as well as potential pathways have been reviewed by Liao et al. [73]. Only one paper compared the effect of polysaccharides from white and red ginseng, which stated that there was a better effect of red ginseng polysaccharides against cell death [74].

It is clear that both WG and RG may share biological activities at a cellular level ( $\bullet$ Fig. $\mathbf{3}$ ). At a human clinical level, however, the traditional therapeutic indications of these two herbal drugs differ (CP 2015). Based on the data we collected, we cannot fully justify 


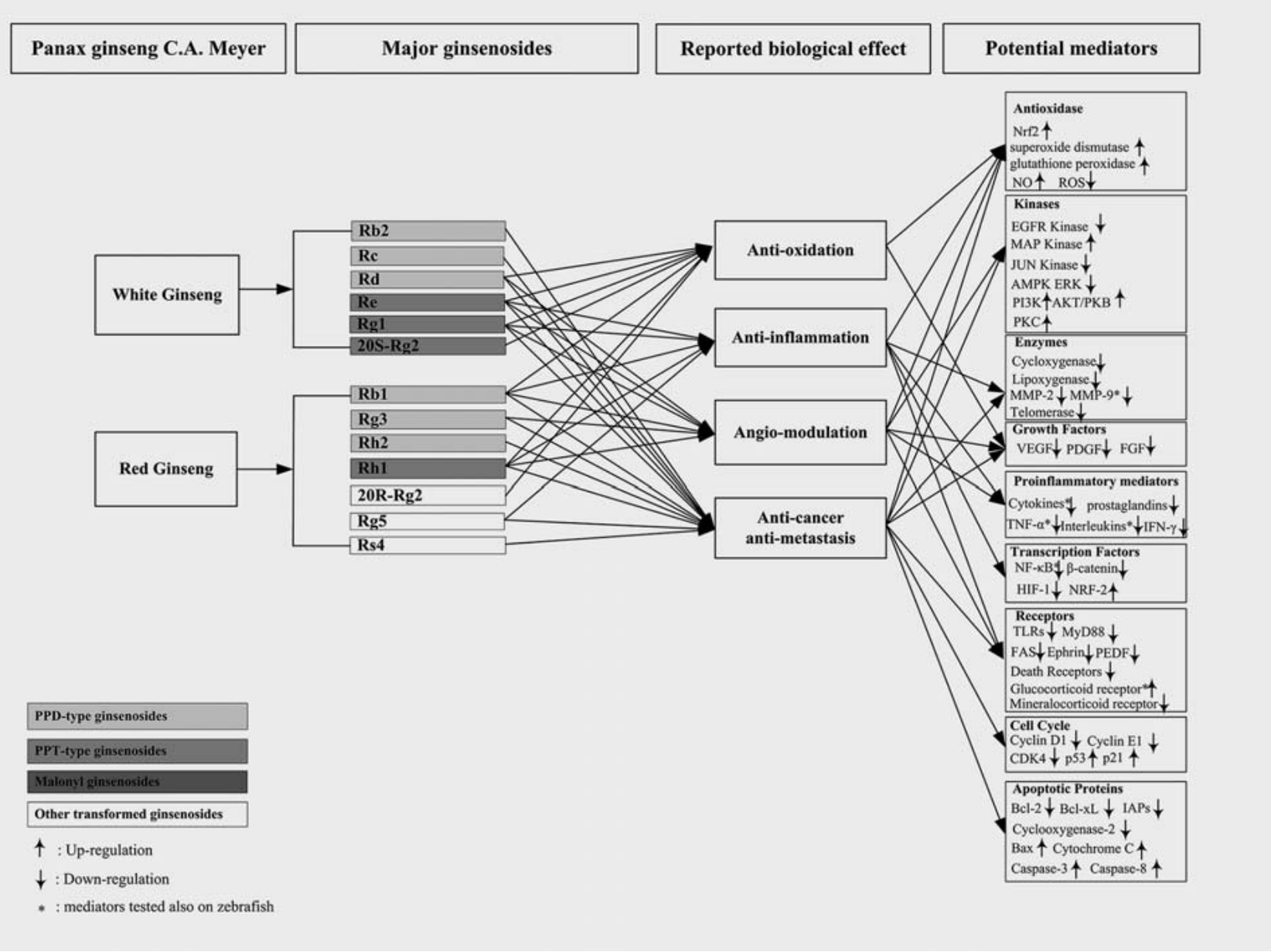

- Fig. 3 Cross-talking of WG and RG. Reported major ginsenosides presented a relatively high content in WG and RG, and their biological activities are correlated with their relative concentrations present in either WG or RG. Details of the references are in the text.

why and how these two herbal forms have so many multiple biological effects that overlap in some cases and differ in others. Possibly, from a systems biology perspective, we can analyze our data using a reverse pharmacological approach that may provide an opportunity to reveal and explore "how" and "why" from the known traditional experience by integrating systems information. It is also important to consider that all current pharmacological studies of ginseng focus mainly on a limited number of ginsenosides that are available commercially or readily acquired, such as $\mathrm{Rg} 1, \mathrm{Rb} 1, \mathrm{Rh} 1, \mathrm{Rh} 2$, and $\mathrm{Rg} 3$, while the vast majority of ginsenosides have not been evaluated. Additionally, Cui et al. [75] mentioned that the oral bioavailability of ginsenosides is low for protopanaxatril and protopanaxadiol in human urine. The other important aspect is the role of microflora in the human digestive system for the bioconversion/metabolism of ginsenosides, as Kong et al. reported [17]. Therefore, bioavailability is also very important and may contribute to the bioactivities of WG and RG [38]. A further comparative study between RG and WG should also be taken into consideration from this perspective. In short, investigating WG and RG individually may shed light on the difference in a potential mechanism(s) that correlates to their therapeutic applications and characteristic component(s). Furthermore, investigations on
WG and RG may contribute to the development of strategies for new personalized interventions and the discovery of novel drugs.

\section{Interactions of Ginseng with other Drugs}

Ginseng is a popular herbal drug that is used worldwide. Thus, from the consumer safety perspective, it is important that full information and awareness of the interactions of ginseng with other herbs and medicines is readily accessible. According to the ancient book Shennong bencao jing, ginseng is considered to be a superior herbal drug with low toxicity. However, based on the records of Chinese medical applications, the use of ginseng together with some specific herbs such as Veratrum nigrum L. should be avoided altogether as it can reduce or even reverse the therapeutic function of ginseng. Such interactions have recently been supported by scientific evidence [76]. There are also some other descriptions of interactions between ginseng and food in Chinese practice, for instance, the consumption of radish (Raphanus sativus L.) may reduce the nourishing effect of ginseng. Further scientific research focused on these topics is needed to reveal other contraindications or interactions of ginseng. In addition, some clinical case reports have mentioned the interaction between ginseng with 
some chemical drugs such as warfarin with RG [77] and phenelzine [78].

\section{Effect of the Combination of Ginseng Extracts with other (herbal) Medicines}

Few studies related to combinations with ginseng include any reference to which type, WG or RG, was used for the research. According to Chinese medicinal practice, ginseng can be used alone or in combination with other herbs. For example, the formula "Zhu-Xiang", an herb mixture that contains ginseng and other herbs such as safflower (Carthamus tinctorius L., Compositae), has an antitumor effect to inhibit the proliferation of breast cancer cells [79]. Not only as an anticancer drug, but also as a drug against other diseases, ginseng combined with other herbal medicines has been reported to have benefits. Gincosan is a famous mixture of $P$. ginseng C. A. Meyer and Ginkgo biloba L. extracts that is frequently used to improve cognitive functions [80]. For instance, it can increase serotonin and decrease noradrenaline levels in the brain, and increase serum ACTH levels, thus being beneficial for the brain and improving learning behavior and secondary memory [81-83]. A combination of a ginseng extract with guarana [Paullinia cupana (Mart.) Ducke] has been reported to improve attention and memory [84]. Dry ginseng extracts with aluminium hydroxide or mineral oil have been found to synergistically act as vaccine adjuvants that can enhance immune responses, while Rb1 and $\mathrm{Rg} 1$ were observed to act antagonistically and partially inhibit each other $[85,86]$. In another case, combination therapy with ginseng and sodium ozagrel was reported to be more effective as a neuroprotective for the treatment of transient cerebral ischemia since it enhanced neuronal cell survival and inhibited astrocytes expansion [87].

Red ginseng acidic polysaccharides, in combination with chemotherapeutic agents such as cyclophosphamide, pidotimod, and paclitaxel (taxol), have multiple immunomodulatory effects as well as antitumor and chemoprotection activities $[39,88,89]$. The RG acidic polysaccharide in combination with IFN- $y$ can stimulate macrophage function by increasing the production of IL-1, IL-6, NO, and TNF- $\alpha$ and activating NF- $\kappa B[90,91]$. The activation of SCF and GM-CSF are also involved in these mechanisms [88]. In combination with rlL-2, the acidic polysaccharide can also induce Th1 cell and macrophage cytokines and generate LAK cells [92].

\section{Synergistic Effects of Ginsenoside(s) with synthetic Pharmaceuticals}

The simultaneous administration of Rg3 with docetaxel, paclitaxel, cisplatin, and doxorubicin showed a synergistic effect against colon cancer cell growth and apoptosis via inhibition of NF-KB [93], while its combination with cyclophosphamide exhibited a synergistic effect against ovarian cancer, prolonging the life of mice and reducing microvessel density and VEGF levels [94]. Combining Rg3 with gemcitabine or cyclophosphamide was reported to inhibit angiogenesis and growth of lung cancer and improve the survival and quality of life of mice $[95,96]$. Compound $\mathrm{K}$ in combination with gamma ray radiation was observed to induce apoptosis, nuclear fragmentation, loss of mitochondrial membrane potential, and activate caspase 3 , and enhance regression of tumor xenografts for cancer therapy [97]. The combination of
Rg1 with Bt2cAMP was reported to synergistically downregulate the GR by induction of the luciferase reporter gene [46]. Mixtures of 20-protopanaxatriol with $\mathrm{Rg} 1$ or Rb1 acted synergistically, showing antioxidant activity inducing the Nrf2-antioxidant response element [98]. The abundance of Rg1 in WG and Rg3 and $\mathrm{Rb} 2$ in RG may contribute to their antitumor activity, and RG plus 5 -fluorouracil has been reported to have a better antiproliferative effect on human colorectal cancer than the combination of WC combined with 5-fluorouracil [70]. This difference in antitumor effect of WG and RG may reflect different bioresponses. This goes to prove that it is critical to distinguish which ginseng, WG or RG, is used in bioactivity studies since the results will provide better guidance for the clinical applications of ginseng, as well as for the design of synergistic combinations for cancer treatment and chemotoxic prevention.

\section{Zebrafish as a Model for Research on the Effect of Red Ginseng and White Ginseng on Immunomodulation}

As can be observed in our summary in $>$ Table 2 , different and even contradictory biological responses have been reported for ginseng. As mentioned before, the use of different ginseng materials (RG or WG) or cell-based assay systems could account for this. Alternatives such as in vivo investigations combined with the reverse pharmacology approach could provide novel insight into the biological effects of herbal medicine to obtain more accurate and consistent results. This requires the use of more advanced techniques and high-throughput models that provide sufficient reliable data. Among these, animal models such as zebrafish fulfill many of these requirements. Zebrafish is a widely used model that has emerged in recent years for the study of multiple disorders and is considered to be a rapid and high-throughput drug screening system $[99,100]$. According to the strict European and American animal welfare regulations on the protection of animals used for scientific studies, the zebrafish (particularly the earlier life stage embryos/larvae) model is considered a replacement or refinement method, and has become a popular model for biomedical and toxicology/pharmacology research. The immune system of zebrafish is remarkably similar to that of humans, and thus this animal model is increasingly used to study inflammatory and infectious diseases or other disorders in which the immune system plays a major role, such as diabetes and cancer [101-103]. Zebrafish embryos develop into the larval stage within only 3 days. The first cells of the immune system appear on the first day after fertilization of the eggs, and within the next 2 days, both macrophages and neutrophils are present. The millimetric size of zebrafish embryos and larvae makes the experimental conditions easier, since only low quantities of drugs are needed and administration through the medium is simple. Macrophages and neutrophils, which are the main immune cell types orchestrating the innate immune response, can be fluorophore-marked using different transgenic lines, such as $\mathrm{Tg}$ (mpeg:mcherry) and $\mathrm{Tg}$ (mpx:GFP) $[104,105]$. Such transgenic models are convenient for the dynamic visualization of the behavior and interactions of 
A).

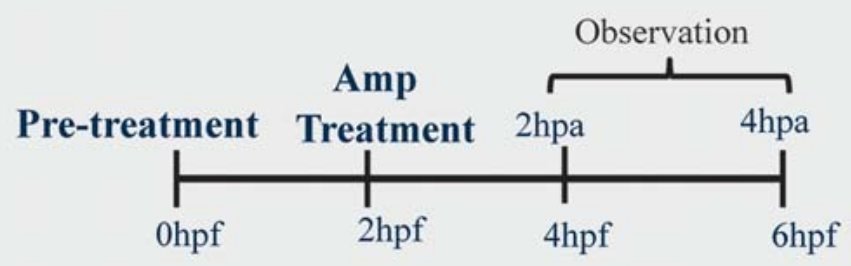

B).

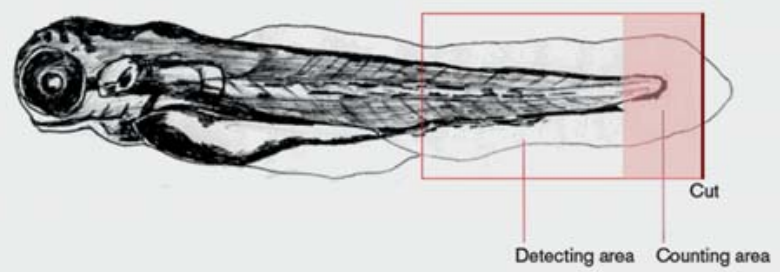

C).

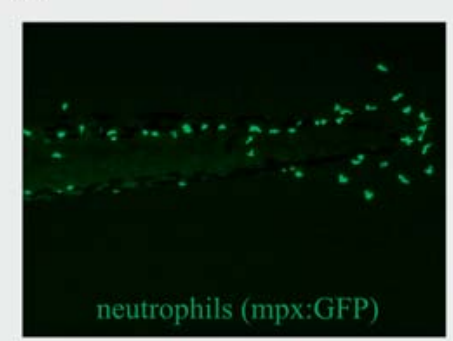

D).

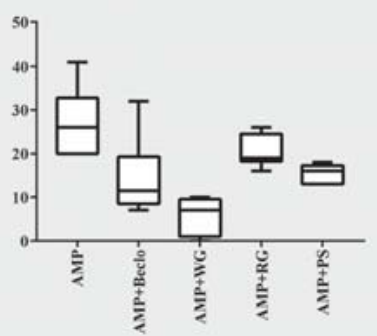

AMP: Zebrafish tail fin amputation model Beclo: Beclomethasone

WG: Ginsenosides extracted from White Ginseng RG: Ginsenosides extracted from Red Ginseng

PS: Polysaccharides from Ginseng

- Fig. 4 Recent results of a pilot study on the comparative activity of WG and RG extracts on neutrophil migration using the zebrafish tail-fin amputation model. A General scheme of the tail-fin amputation (Amp) zebrafish model with drug treatment. The zebrafish larvae used for this assay are at 3 days post-fertilization. After $2 \mathrm{~h}$ pretreatment with either WG, RG, or beclomethasone (positive control), the larvae tail fin is cut and the same drug treatment is repeated immediately. At least two time points ( 2 or $4 \mathrm{~h}$ post-amputation) are selected for further microscopic observation or bioassays. B Schematic figure of the zebrafish larva indicating the position of the tail cut and the areas used for detecting and counting the neutrophils. C Representative images showing the migration of neutrophils towards the cut edge after tail-fin amputation (4 h post-amputation). D Preliminary results of the anti-inflammatory activity of WG vs. RG, compared to beclomethasone; the $y$-axis indicates the number of neutrophils that migrated to the tail cut edge at $4 \mathrm{~h}$ post-amputation.

innate immune cells in a living organism, which is especially useful for inflammation and cancer studies [106, 107].

The zebrafish tail-fin amputation model is a validated inflammatory model with visible innate immune system activation (migration of macrophages and neutrophils) [106]. Such a model is well suited for studies of ginseng/ginsenoside(s) to visually screen for anti-inflammatory activity. - Fig. 4 shows an example of preliminary results using this model, suggesting that WG has an anti-inflammatory effect that is stronger than that of beclomethasone, while RG shows no significant effect. Potentially different mechanisms might be involved, and other indicators of inflammation, such as the expression of proinflammatory and anti-inflammatory genes, level of protein and lipid mediators of inflammation, and post-translation modification of key enzymes, have yet to be studied. The potential phagocytic function of macrophages of ginseng extracts has been evaluated recently using a different zebrafish model [108].

\section{Summary and Conclusions}

Current scientific methods for drug discovery and development include the use of advanced techniques such as genomics, pro- teomics, metabolomics, and combinations of biochemistry, biomedicine, computing statistics, and high-throughput assays. Despite the success of these in many fields, a shift in paradigm in the approach to novel drug discovery is urgently needed, and the reverse pharmacology approach provides a very interesting option. Natural herbal medicines that have been validated by ancient wisdom derived from traditional use offer great potential for novel drug discovery or treatment strategies thanks to their long history of clinical applications on humans with renown effectiveness but lack a clear knowledge of the molecular basis for their mechanisms of action. Reverse pharmacology can provide alternative routes to identify significant candidates and to understand potential bioactivities, as well as to enhance the efficacy and reduce the toxicity for advanced treatment strategies [109].

Ginseng is a widely used herb with diverse indications in Asian countries and its chemical composition and pharmacological activities have attracted the attention of researchers in the past decades. It is rich in many different ginsenosides and polysaccharides, the content of which may vary both qualitatively and quantitatively according to the steaming processing used for post-harvest treatments. These differences may be beneficial since they can presumably also have different bioactivities, participating in vari- 
ous signaling pathways related to immunomodulation. The emphasis of ginseng studies on efficacy in the future should distinguish the material that is being tested, WG or RG, since results would be more comparable and could provide a more reliable guide in the search of new active compounds as well as contribute to the discovery of synergistic effects and their multiple targeting mechanisms on immunomodulation.

Extending the knowledge of the cellular level to organs and the human body requires a multilevel approach. This can be achieved using reverse pharmacology, an emerging approach that has revolutionized the experimental design of studies aimed at discovering potential drugs or treatments and has been applied successfully to traditional medicine. Additionally, the need of highthroughput techniques and animal models is imperative to understand efficacy and the mechanisms of action of component(s)/ combinations. For this, the development of a vertebrate animal model such as zebrafish has provided a visible, simple way to evaluate drug efficacy on immunomodulation, requiring relatively small amounts of samples that are easily administered. The combination of this pharmacological approach and the availability of an animal model such as the zebrafish should greatly increase our understanding of the biological activities of both WG and RG at an integrated system level.

\section{Acknowledgements}

Many thanks to Marcel Schaaf for advice on the zebrafish inflammation assay. We are also grateful to Dr. Y.H. Choi and Dr. E. R. Wilson for the critical reading of the manuscript and scientific discussion. Many thanks to Anna June van Duijn and Julia July van Duijn for providing the designed structural figure of the zebrafish ( $\triangleright$ Fig. 4 B). Authors S. Liu and X. Huang acknowledge the Science and Technology Development Plan Project of Jilin Province, International Cooperation Project (Project No. 20170414027GH)

\section{Conflict of Interest}

The authors declare no conflict of interest.

\section{References}

[1] Yun TK. Brief introduction of Panax ginseng C. A. Meyer. J Korean Med Sci 2001; 16 (Suppl.): S3-S5

[2] Chinese Pharmacopoeia Commission. Pharmacopoeia of the People's Republic of China. Beijing, China: China Medical Science Press; 2015

[3] Korean Pharmacopoeia Committee. The Korean Pharmacopoeia. Seoul: Shinibooks; 2013

[4] Japanese Pharmacopoeia Editorial Committee. The Japanese Pharmacopoeia. 16th edition. Tokyo: Hirokawa Book Co.; 2011

[5] Wang M, Franz G. The role of the European Pharmacopoeia (Ph Eur) in quality control of traditional Chinese herbal medicine in European member states. WJTCM 2015; 1: 5-15

[6] Du QQ, Liu SY, Xu RF, Li M, Song FR, Liu ZQ. Studies on structures and activities of initial Maillard reaction products by electrospray ionisation mass spectrometry combined with liquid chromatography in processing of red ginseng. Food Chem 2012; 135: 832-838

[7] Zhang C, Li L, Xiao Y. Approaches to revealing the relation between the processing and property of Chinese medicines. World Sci Technol 2010; 12: $876-881$
[8] Sun M, Chang WT, Van Wijk E, He M, Koval S, Lin MK, Van Wijk R, Hankemeier T, van der Greef J, Wang M. Biology Characterization of the therapeutic properties of Chinese herbal materials by measuring delayed luminescence and dendritic cell-based immunomodulatory response. J Photochem Photobiol B 2017; 168: 1-11

[9] Ung CY, Li H, Cao ZW, Li YX, Chen YZ. Are herb-pairs of traditional Chinese medicine distinguishable from others? Pattern analysis and artificial intelligence classification study of traditionally defined herbal properties. J Ethnopharmacol 2007; 111: 371-377

[10] Pang J, Zhu X, Liu Y, Fu J, Zhao X, Yang M, van Wijk E, Wang M, Nie X, Han J. Spectral analysis of Chinese medicinal herbs based on delayed luminescence. Evid Based Complement Alternat Med 2016; 2016: 846024

[11] Dharmananda S. The Nature of Ginseng: from traditional Use to modern Research. Portland, Oregon: ITM; 2002

[12] Yang WZ, Ye M, Qiao X, Liu CF, Miao WJ, Bo T, Tao HY, Guo DA. A strategy for efficient discovery of new natural compounds by integrating orthogonal column chromatography and liquid chromatography/mass spectrometry analysis: Its application in Panax ginseng, Panax quinquefolium and Panax notoginseng to characterize 437 potential ginsenosides. Anal Chim Acta 2012; 739: 56-66

[13] Vo H, Ghimeray A, Vu NT, Jeong YH. Quantitative estimation of ginsenosides in different ages of Panax vietnamensis and their anti-proliferation effects in hela cells. Afr J Tradit Complement Altern Med 2015; 12: 79

[14] Wong AS, Che CM, Leung KW. Recent advances in ginseng as cancer therapeutics: a functional and mechanistic overview. Nat Prod Rep 2015; 32: 256-272

[15] Xiu Y, Ma L, Zhao H, Sun X, Li X, Liu S. Differentiation and identification of ginsenoside structural isomers by two-dimensional mass spectrometry combined with statistical analysis. J Ginseng Res, advance online publication 26 November 2017. doi:10.1016/j.jgr.2017.11.002

[16] Wu W, Sun L, Zhang Z, Guo Y, Liu S. Profiling and multivariate statistical analysis of Panax ginseng based on ultra-high-performance liquid chromatography coupled with quadrupole-time-of-flight mass spectrometry. J Pharm Biomed Anal 2015; 107: 141-150

[17] Kong H, Wang M, Venema K, Maathuis A, van der Heijden R, van der Greef J, Xu G, Hankemeier T. Bioconversion of red ginseng saponins in the gastro-intestinal tract in vitro model studied by high-performance liquid chromatography-high resolution Fourier transform ion cyclotron resonance mass spectrometry. J Chromatogr A 2009; 1216: 2195-2203

[18] Angelova N, Kong HW, van der Heijden R, Yang SY, Choi YH, Kim HK, Wang M, Hankemeier T, van der Greef J, Xu G, Verpoorte R. Recent methodology in the phytochemical analysis of ginseng. Phytochem Anal 2008; 19: 2-16

[19] Xiu Y, Li X, Sun X, Xiao D, Miao R, Zhao H, Liu S. Simultaneous determination and difference evaluation of 14 ginsenosides in Panax ginseng roots cultivated in different areas and ages by high-performance liquid chromatography coupled with triple quadrupole mass spectrometer in the multiple reaction-monitoring mode combined with multivariate statistical analysis. J Ginseng Res 2017. doi:10.1016/j.jgr.2017.12.001

[20] Soldati F, Tanaka O. Panax ginseng: relation between age of plant and content of ginsenosides. Planta Med 1984; 51: 351-352

[21] Shi W, Wang Y, Li ], Zhang H, Ding L. Investigation of ginsenosides in different parts and ages of Panax ginseng. Food Chem 2007; 102: 664-668

[22] Li XG, Yan YZ, Jin X], Kim YK, Uddin MR, Kim YB, Bae H, Kim YC, Lee SW, Park SU. Ginsenoside content in the leaves and roots of Panax ginseng at different ages. Life Sci J 2012; 9: 679-683

[23] Soldati F, Sticher O. HPLC separation and quantitative determination of ginsenosides from Panax ginseng, Panax quinquefolium and from ginseng drug preparations. 2nd communication. Planta Med 1980; 39: 348-357

[24] Kang OJ, Kim JS. Comparison of ginsenoside contents in different parts of Korean ginseng (Panax ginseng C.A. Meyer). Prev Nutr Food Sci 2016; 21: 389-392 
[25] Liu J, Liu Y, Zhao L, Zhang ZH, Tang ZH. Profiling of ginsenosides in the two medicinal Panax herbs based on ultra-performance liquid chromatography-electrospray ionization-mass spectrometry. Springerplus 2016; 5: 1770

[26] Wu W, Sun L, Zhang Z, Guo Y, Liu S. Profiling and multivariate statistical analysis of Panax ginseng based on ultra-high-performance liquid chromatography coupled with quadrupole-time-of-flight mass spectrometry. J Pharm Biomed Anal 2015; 107: 141-150

[27] Lee JW, Ji SH, Lee YS, Choi DJ, Choi BR, Kim GS, Baek NI, Lee DY. Mass spectrometry based profiling and imaging of various ginsenosides from Panax ginseng roots at different ages. Int J Mol Sci 2017; 18: E1114

[28] Hu C, Wei H, Kong H, Bouwman J, Gonzalez-Covarrubias V, van der Heijden R, Reijmers TH, Bao X, Verheij ER, Hankemeier T, Xu G, van der Greef J, Wang M. Linking biological activity with herbal constituents by systems biology-based approaches: effects of Panax ginseng in type 2 diabetic Goto-Kakizaki rats. Mol Biosyst 2011; 7: 3094-3103

[29] Zhang HM, Li SL, Zhang H, Wang Y, Zhao ZL, Chen SL, Xu HX. Holistic quality evaluation of commercial white and red ginseng using a UPLCQTOF-MS/MS-based metabolomics approach. J Pharm Biomed Anal 2012; 62: 258-273

[30] Meyer A, Shibata S. Chemistry and cancer preventing activities of ginseng saponins and some related triterpenoid compounds. J Korean Med Sci 2001; 16 (Suppl.): S28-S37

[31] Kitagawa I, Taniyama T, Shibuya H, Noda T, Yoshikawa M. Chemical studies on crude drug processing. $\mathrm{V}$. On the constituents of ginseng radix rubra (2): Comparison of the constituents of white ginseng and red ginseng prepared from the same Panax ginseng root (in Japanese). Yakugaku Zasshi 1987; 107: 495-505

[32] Kitagawa I, Yoshikawa M, Yoshihara T, Hayashi T, Taniyama T. [Chemical studies of crude drugs (1). Constituents of Ginseng radix rubra] (in Japanese). Yakugaku Zasshi 1983; 103: 612-622

[33] Kite GC, Howes MR, Leon C], Simmonds MS]. Liquid chromatography/ mass spectrometry of malonyl-ginsenosides in the authentication of ginseng. Rapid Commun Mass Spectrom 2003; 17: 238-244

[34] Kim WY, Kim JM, Han SB, Lee SK, Kim ND, Park MK, Kim CK, Park JH. Steaming of ginseng at high temperature enhances biological activity. J Nat Prod 2000; 63: 1702-1704

[35] Xu X, Gao Y, Xu S, Liu H, Xue X, Zhang Y, Zhang H, Liu M, Xiong H, Lin R, Li X. Remarkable impact of steam temperature on ginsenosides transformation from fresh ginseng to red ginseng. J Ginseng Res 2017. doi:10.1016/j.jgr.2017.02.003

[36] Xue P, Yao Y, Yang XS, Feng J, Ren GX. Improved antimicrobial effect of ginseng extract by heat transformation. J Ginseng Res 2017; 41: 180187

[37] Kim SJ, Shin JY, Ko SK. Changes in the contents of prosapogenin in Red ginseng (Panax ginseng) depending on the extracting conditions. J Ginseng Res 2016; 40: 86-89

[38] Kim EO, Cha KH, Lee EH, Kim SM, Choi SW, Pan CH, Um BH. Bioavailability of ginsenosides from white and red ginsengs in the simulated digestion model. J Agric Food Chem 2014; 62: 10055-10063

[39] Ha DC, Ryu GH. Chemical components of red, white and extruded root ginseng. J Korean Soc Food Sci Nutr 2005; 34: 247-254

[40] Lee SM, Bae BS, Park HW, Ahn NG, Cho BG, Cho YL, Kwak YS. Characterization of Korean Red Ginseng (Panax ginseng Meyer): History, preparation method, and chemical composition. J Ginseng Res 2015; 39: 384391

[41] Li X, Zheng Y, Liu M, Zhang L. [A study on maillard reaction and its products during processing of red ginseng]. China J Chinese Mater medica 1999; 24: 274-278, 318

[42] Jung MY, Jeon BS, Bock JY. Free, esterified, and insoluble-bound phenolic acids in white and red Korean ginsengs (Panax ginseng C. A. Meyer). Food Chem 2002; 79: 105-111
[43] Abd El-Aty AMA, Kim IK, Kim MR, Lee C, Shim JH. Determination of volatile organic compounds generated from fresh, white and red Panax ginseng (C. A. Meyer) using a direct sample injection technique. Biomed Chromatogr 2008; 22: 556-562

[44] Kang S, Min H. Ginseng, the "Immunity Boost": The effects of Panax ginseng on immune system. J Ginseng Res 2012; 36: 354-368

[45] Yue PY, Mak NK, Cheng YK, Leung KW, Ng TB, Fan DT, Yeung HW, Wong RN. Pharmacogenomics and the Yin/Yang actions of ginseng: anti-tumor, angiomodulating and steroid-like activities of ginsenosides. Chin Med 2007; 2: 6

[46] Chung E, Lee KY, Lee Y, Lee YH, Lee SK. Ginsenoside-Rg1 down-regulates glucocorticoid receptor and displays synergistic effects with cAMP. Steroids 1998; 63: 421-424

[47] Du J, Cheng B, Zhu X, Ling C. Ginsenoside Rg1, a novel glucocorticoid receptor agonist of plant origin, maintains glucocorticoid efficacy with reduced side effects. J Immunol 2011; 187: 942-950

[48] Lee Y, Chung E, Lee KY, Lee YH, Huh B, Lee SK. Ginsenoside-Rg1, one of the major active molecules from Panax ginseng, isa functional ligand of glucocorticoid receptor. Mol Cell Endocrinol 1997; 133: 135-140

[49] Sung WN, Kwok HH, Rhee MH, Yue PYK, Wong RNS. Korean Red Ginseng extract induces angiogenesis through activation of glucocorticoid receptor.J GINS RES 2016; 41: 477-486

[50] Sengupta S, Toh SA, Sellers LA, Skepper JN, Koolwijk P, Leung HW, Yeung HW, Wong RN, Sasisekharan R, Fan TP. Modulating angiogenesis: the yin and the yang in ginseng. Circulation 2004; 110: 1219-1225

[51] Yu S, Zhou X, Li F, Xu C, Zheng F, Li ], Zhao H, Dai Y, Liu S, Feng Y. Microbial transformation of ginsenoside Rb1, Re and Rg1 and its contribution to the improved anti-inflammatory activity of ginseng. Sci Rep 2017; 7: 138

[52] Hyun MS, Hur JM, Shin YS, Song B], Mun Y], Woo WH. Comparison study of white ginseng, red ginseng, and fermented red ginseng on the protective effect of LPS-induced inflammation in RAW 264.7 cells. J Appl Biol Chem 2009; 52: 21-27

[53] Jang A, Sueng YC, Ji ]. The comparative study on physiological activity of White ginseng, Red ginseng and Black ginseng extract. J Digit Converg 2016; 14: 459-471

[54] Jin Y, Kim Y], Jeon JN, Wang C, Min JW, Noh HY, Yang DC. Effect of white, red and black ginseng on physicochemical properties and ginsenosides. Plant Foods Hum Nutr 2015; 70: 141-145

[55] Kim Y], Kim DW, Chang CC. Carbon tetrachloride (CCl4)-induced mouse liver damage and antioxidant activities of aqueous extracts of white, red, and fermented red ginseng. J Trace Anal Food Drugs 2013; 1: 22-29

[56] Sohn SH, Kim SK, Kim YO, Kim HD, Shin YS, Yang SO, Kim SY, Lee SW. A comparison of antioxidant activity of Korean White and Red Ginsengs on H2O2-induced oxidative stress in HepG2 hepatoma cells. J Ginseng Res 2013; 37: 442-450

[57] Lim CY, Moon JM, Kim BY, Lim SH, Lee GS, Yu HS, Cho SI. Comparative study of Korean White Ginseng and Korean Red Ginseng on efficacies of Ova-induced asthma model in mice. J Ginseng Res 2015; 39: 38-45

[58] Lee $\mathrm{CH}$, Kim JH. A review on the medicinal potentials of ginseng and ginsenosides on cardiovascular diseases. J Ginseng Res 2014; 38: 161-166

[59] Leung KW, Pon YL, Wong RN, Wong AS. Ginsenoside-Rg1 induces vascular endothelial growth factor expression through the glucocorticoid receptor-related phosphatidylinositol 3-kinase/Akt and beta-catenin/T-cell factor-dependent pathway in human endothelial cells. J Biol Chem 2006; 281: 36280-36288

[60] Helms S. Cancer prevention and therapeutics: Panax ginseng. Altern Med Rev 2004; 9: 259-274

[61] Wang CZ, Anderson S, Du W, He TC, Yuan CS. Red ginseng and cancer treatment. Chin J Nat Med 2016; 14: 7-16

[62] Yun TK. Panax ginseng - a non-organ-specific cancer preventive? Lancet Oncol 2001; 2: 49-55 
[63] Xiaoguang C, Hongyan L, Xiaohong L, Zhaodi F, Yan L, Lihua T, Rui H. Cancer chemopreventive and therapeutic activities of red ginseng. J Ethnopharmacol 1998; 60: 71-78

[64] Jin X, Che DB, Zhang ZH, Yan HM, Jia ZY, Jia XB. Ginseng consumption and risk of cancer: A meta-analysis. J Ginseng Res 2015; 40: 269-277

[65] Yue PYK, Mak NK, Cheng YK, Leung KW, Ng TB, Fan DTP, Yeung HW, Wong RNS. Pharmacogenomics and the Yin/Yang actions of ginseng: anti-tumor, angiomodulating and steroid-like activities of ginsenosides. Chin Med 2007; 2: 6

[66] Nag SA, Qin J], Wang W, Wang MH, Wang H, Zhang RW. Ginsenosides as anticancer agents: In vitro and in vivo activities, structure-activity relationships, and molecular mechanisms of action. Front Pharmacol 2012; 3: 25

[67] Cheong JH, Kim H, Hong M], Yang MH, Kim JW, Yoo H, Yang H, Park JH, Sung SH, Kim HP, Kim J. Stereoisomer-specific anticancer activities of ginsenoside Rg3 and Rh2 in HepG2 cells: disparity in cytotoxicity and autophagy-inducing effects due to 20(S)-epimers. Biol Pharm Bull 2015; 38: 102-108

[68] Park YC, Lee CH, Kang HS, Kim KW, Chung HT, Kim HD. Ginsenoside-Rh1 and $\mathrm{Rh} 2$ inhibit the induction of nitric oxide synthesis in murine peritoneal macrophages. Biochem Mol Biol Int 1996; 40: 751-757

[69] Kim Y], Yamabe N, Choi P, Lee JW, Ham J, Kang KS. Efficient thermal deglycosylation of ginsenoside Rd and its contribution to the improved anticancer activity of ginseng. J Agric Food Chem 2013; 61: 9185-9191

[70] Fishbein AB, Wang CZ, Li XL, Mehendale SR, Sun S, Aung HH, Yuan CS. Asian ginseng enhances the anti-proliferative effect of 5-fluorouracil on human colorectal cancer: comparison between white and red ginseng. Arch Pharm Res 2009; 32: 505-513

[71] Byeon SE, Lee J, Kim JH, Yang WS, Kwak YS, Kim SY, Choung ES, Rhee $\mathrm{MH}$, Cho JY. Molecular mechanism of macrophage activation by red ginseng acidic polysaccharide from Korean red ginseng. Mediators Inflamm 2012; 2012: 732860

[72] Wan D, Jiao L, Yang H, Liu S. Structural characterization and immunological activities of the water-soluble oligosaccharides isolated from the Panax ginseng roots. Planta 2012; 235: 1289-1297

[73] Liao JF, Shen YC, Huang YT, Chen CF. Pharmacology of polysaccharides from ginseng species. Int J Biomed Pharm Sci 2012; 6: 63-69

[74] Yang SH, Seo SH, Kim SW, Choi SK, Kim DH. Effect of ginseng polysaccharide on the stability of lactic acid bacteria during freeze-drying process and storage. Arch Pharm Res 2006; 29: 735-740

[75] Cui JF, Björkhem I, Eneroth P. Gas chromatographic-mass spectrometric determination of 20(S)-protopanaxadiol and 20(S)-protopanaxatriol for study on human urinary excretion of ginsenosides after ingestion of ginseng preparations. J Chromatogr B Biomed Sci Appl 1997; 689: 349-355

[76] Xu Y, Ding J, An JN, Qu YK, Li X, Ma XP, Zhang YM, Dai G], Lin N. Effect of the interaction of Veratrum nigrum with Panax ginseng on estrogenic activity in vivo and in vitro. Sci Rep 2016; 6: 26924

[77] Janetzky K, Morreale AP. Probable interaction between warfarin and ginseng. Am J Health Syst Pharm 1997; 54: 692-693

[78] Jones BD, Runikis AM. Interaction of ginseng with phenelzine. J Clin Psychopharmacol 1987; 7: 201-202

[79] Loo WT, Cheung MN, Chow LW. The inhibitory effect of a herbal formula comprising ginseng and Carthamus tinctorius on breast cancer. Life Sci 2004; 76: 191-200

[80] Williamson EM. Synergy and other interactions in phytomedicines. Phytomedicine 2001; 8: 401-409

[81] Petkov VD, Hadjiivanova C, Petkov VV, Milanov S, Visheva N, Boyadjieva N. Effects of standardized extracts GK501, from Ginkgo biloba L., G115 from Panax ginseng C. A. Meyer, and their combination, gincosan (PHL00701), on the brain levels of biogenic monoamines and on the serum content of prolactin, growth hormone and ACTH. Phyther Res 1993; 7 : 139-145
[82] Petkov VD, Kehayov R, Belcheva S, Konstantinova E, Petkov VV, Getova D, Markovska V. Memory effects of standardized extracts of Panax ginseng (G115), Ginkgo biloba (GK 501) and their combination Gincosan (PHL-00701). Planta Med 1993; 59: 106-114

[83] Kennedy DO, Scholey AB, Wesnes KA. Differential, dose dependent changes in cognitive performance following acute administration of a Ginkgo biloba/Panax ginseng combination to healthy young volunteers. Nutr Neurosci 2001; 4: 399-412

[84] Kennedy DO, Haskell CF, Wesnes KA, Scholey AB. Improved cognitive performance in human volunteers following administration of guarana (Paullinia cupana) extract: comparison and interaction with Panax ginseng. Pharmacol Biochem Behav 2004; 79: 401-411

[85] Rivera E, Hu S, Concha C. Ginseng and aluminium hydroxide act synergistically as vaccine adjuvants. Vaccine 2003; $21: 1149-1157$

[86] Song X, Bao S, Wu L, Hu S. Ginseng stem-leaf saponins (GSLS) and mineral oil act synergistically to enhance the immune responses to vaccination against foot-and-mouth disease in mice. Vaccine 2009; 27: 51-55

[87] Park SI, Jang DK, Han YM, Sunwoo YY, Park MS, Chung YA, Maeng LS, Im R, Kim MW, Jeun SS, Jang KS. Effect of combination therapy with sodium ozagrel and Panax ginseng on transient cerebral ischemia model in rats. J Biomed Biotechnol 2010; 2010: 893401

[88] Shim JY, Han Y, Ahn JY, Yun YS, Song JY. Chemoprotective and adjuvant effects of immunomodulator ginsan in cyclophosphamide-treated normal and tumor bearing mice. Int J Immunopathol Pharmacol 2007; 20: 487-497

[89] Du XF, jiang CZ, Wu CF, Won EK, Choung SY. Synergistic immunostimulating activity of pidotimod and red ginseng acidic polysaccharide against cyclophosphamide-induced immunosuppression. Arch Pharm Res 2008; 31: 1153-1159

[90] Choi HS, Kim KH, Sohn E, Park JD, Kim BO, Moon EY, Rhee DK, Pyo S. Red ginseng acidic polysaccharide (RGAP) in combination with IFN- $y$ results in enhanced macrophage function through activation of the NF-KB pathway. Biosci Biotechnol Biochem 2008; 72: 1817-1825

[91] Shin JY, Song JY, Yun YS, Yang HO, Rhee DK, Pyo S. Immunostimulating effects of acidic polysaccharides extract of Panax ginseng on macrophage function. Immunopharmacol Immunotoxicol 2002; 24: 469-482

[92] Kim KH, Lee YS, Jung IS, Park SY, Chung HY, Lee IR, Yun YS. Acidic polysaccharide from Panax ginseng, ginsan, induces Th1 cell and macrophage cytokines and generates LAK cells in synergy with rlL-2. Planta Med 1998; 64: 110-115

[93] Kim SM, Lee SY, Yuk DY, Moon DC, Choi SS, Kim Y, Han SB, Oh KW, Hong IT. Inhibition of NF- $\mathrm{KB}$ by ginsenoside Rg3 enhances the susceptibility of colon cancer cells to docetaxel. Arch Pharm Res 2009; 32: 755-765

[94] Xu TM, Xin Y, Cui MH, Jiang X, Gu LP. Inhibitory effect of ginsenoside Rg3 combined with cyclophosphamide on growth and angiogenesis of ovarian cancer. Chin Med J (Engl) 2007; 120: 584-588

[95] Liu TG, Huang Y, Cui DD, Huang XB, Mao SH, ji LL, Song HB, Yi C. Inhibitory effect of ginsenoside $\mathrm{Rg} 3$ combined with gemcitabine on angiogenesis and growth of lung cancer in mice. BMC Cancer 2009; 9: 250

[96] Hang L, Jun W, Yanfeng G, Wenjun Y, Aiying AS, Meihua C, Chenyu W, Jing J, Shengping Z, Qishan M. Synergistic effects of ginsenoside Rg3 and cyclophosphamine on tumor growth and angiogenesis in lung cancer. African | Biotechnol 2011; 10: 10040-10044

[97] Chae S, Kang KA, Chang WY, Kim MJ, Lee S], Lee YS, Kim HS, Kin DH, Hyun JW. Effect of compound $K$, a metabolite of ginseng saponin, combined with gamma-ray radiation in human lung cancer cells in vitro and in vivo. J Agric Food Chem 2009; 57: 5777-5782

[98] Saw CL, Yang AY, Cheng DC, Boyanapalli SS, Su ZY, Khor TO, Gao S, Wang J, Jiang ZH, Kong AN. Pharmacodynamics of ginsenosides: antioxidant activities, activation of Nrf2, and potential synergistic effects of combinations. Chem Res Toxicol 2012; 25: 1574-1580 
[99] Robertson AL, Holmes GR, Bojarczuk AN, Burgon J, Loynes CA, Chimen M, Sawtell AK, Hamza B, Willson J, Walmsley SR, Anderson SR, Coles MC, Farrow SN, Solari R, Jones S, Prince LR, Irimia D, Rainger GE, Kadirkamanathan V, Whyte MK, Renshaw SA. A zebrafish compound screen reveals modulation of neutrophil reverse migration as an antiinflammatory mechanism. Sci Transl Med 2014; 6: 225ra29

[100] Spaink H, Racz P, Ordas A, Veneman W, Vijver M, Wildwater M, Pieters R, Zope H, Kros A, Kantae V, Krekels E, van der Graaf PH, Hankemeier T. Automated zebrafish toxicology screening: Effect assessment and uptake studies. Toxicol Lett 2015; 238: 32-55

[101] Langenau DM. Cancer and Zebrafish. Cham: Springer International Publishing; 2016

[102] Benard EL, Rougeot ], Racz PI, Spaink HP, Meijer AH. Transcriptomic approaches in the zebrafish model for tuberculosis-insights into hostand pathogen-specific determinants of the innate limmune response. Adv Genet 2016; 95: 217-251

[103] Jiménez-Amilburu V, Jong-Raadsen S, Bakkers J, Spaink HP, Marín-Juez R. GLUT12 deficiency during early development results in heart failure and a diabetic phenotype in zebrafish. J Endocrinol 2015; 224: 1-15
[104] Ellett F, Pase L, Hayman JW, Andrianopoulos A, Lieschke G]. mpeg1 promoter transgenes direct macrophage-lineage expression in zebrafish. Blood 2011; 117: e49-e56

[105] Renshaw SA, Loynes CA, Trushell DMI, Elworthy S, Ingham PW, Whyte MKB. A transgenic zebrafish model of neutrophilic inflammation. Blood 2006; 108: 3976-3978

[106] Chatzopoulou A, Heijmans JPM, Burgerhout E, Oskam N, Spaink HP, Meijer AH, Schaaf MJM. Glucocorticoid-induced attenuation of the inflammatory response in zebrafish. Endocrinology 2016; 157: 2772 2784

[107] Torraca V, Masud S, Spaink HP, Meijer AH. Macrophage-pathogen interactions in infectious diseases: new therapeutic insights from the zebrafish host model. Dis Model Mech 2014; 7: 785-797

[108] Xiao D, Xiu Y, Yue H, Sun X, Zhao H, Liu S. A comparative study on chemical composition of total saponins extracted from fermented and white ginseng under the effect of macrophage phagocytotic function. J Ginseng Res 2017; 41: 379-385

[109] Vaidya ADB. Reverse pharmacology - a paradigm shift for drug discovery and development. Curr Res Drug Discov Orig 2014; 1: 9-44 